\title{
Degradation of citronellol, citronellal and citronellyl acetate by Pseudomonas mendocina IBPse 105
}

\author{
Daniela Tozoni \\ Instituto de Biotecnologia \\ Universidade de Caxias do Sul \\ R. Francisco G. Vargas 1130 \\ Caxias do Sul, RS, Brazil \\ Jucimar Zacaria \\ Instituto de Biotecnologia \\ Universidade de Caxias do Sul \\ R. Francisco G. Vargas 1130 \\ Caxias do Sul, RS, Brazil \\ Regina Vanderlinde \\ Instituto de Biotecnologia \\ Universidade de Caxias do Sul \\ R. Francisco G. Vargas 1130 \\ Caxias do Sul, RS, Brazil
}

Ana Paula Longaray Delamare

Universidade de Caxias do Sul

R. Francisco G. Vargas 1130

Caxias do Sul, RS, Brazil

\section{Sergio Echeverrigaray* \\ Universidade de Caxias do Sul \\ R. Francisco G. Vargas 1130 \\ Caxias do Sul, RS, Brazil \\ E-mail: selaguna@ucs.br}

Financial support: COREDES/FAPERGS, and D. Tozoni held a CAPES scholarship during the development of this work.

Keywords: biodegradation, citronellol catabolism, monoterpenes degradation, P. mendocina.

Abbreviations: GC-MS: gas chromatography-mass spectrometry

The purpose of this work was to stud the biodegradation of citronellol, citronellal and citronellyl acetate by a soil Pseudomonas mendocina strain (IBPse 105) isolated from a Cymbopogon windelandi field. This strain efficiently used citronellol, citronellal, citronellyl acetate and myrcene as sole source of carbon, but was not able to grow on other 15 monoterpenoids evaluated. Gas chromatography-mass spectrometry (GC-MS) analysis of metabolites accumulation during $\boldsymbol{P}$. medocina IBPse 105 growth on citronellol showed that this strain uses the citronellol catabolic pathway described for other species of the genus. IBPse 105 degradation of citronellyl acetate initiates by its hydrolysis to citronellol. The mini-Tn5 insertion in mutant IBPse 105-303, impaired in citronellol degradation, but able to grow on citronellal, was located in a homologous of the $P$. aeruginosa $a t u B$ gene, that codifies citronellol deshydrogenase.
Terpenes or terpenoids are widespread in nature, and are the most important component of the essential oil of many higher plants (Loza-Tavera, 1999). These compounds are characterized by methyl-branched molecular structures derived from isoprene. Monoterpenes and their oxygenated forms consist of two isoprene units (C10), and can be cyclic (1,8-cineole, camphor, etc.) or acyclic (citronellol, geraniol, citral, etc.).

Citronellol, citronellal and citronellyl acetate are among the main constituent of the essential oils of several plants, like citrus, citronella grass, roses, lemongrass, basil, lemon eucalyptus, among others, being responsible for the aromatic and biological properties, including antibacterial activity, of these oils (Hammer et al. 1999; Dorman and Deans. 2000; Bakkali et al. 2008).

Acyclic terpenoids contain a 3-methyl substitution in the

*Corresponding author 
Tozoni, D. et al.

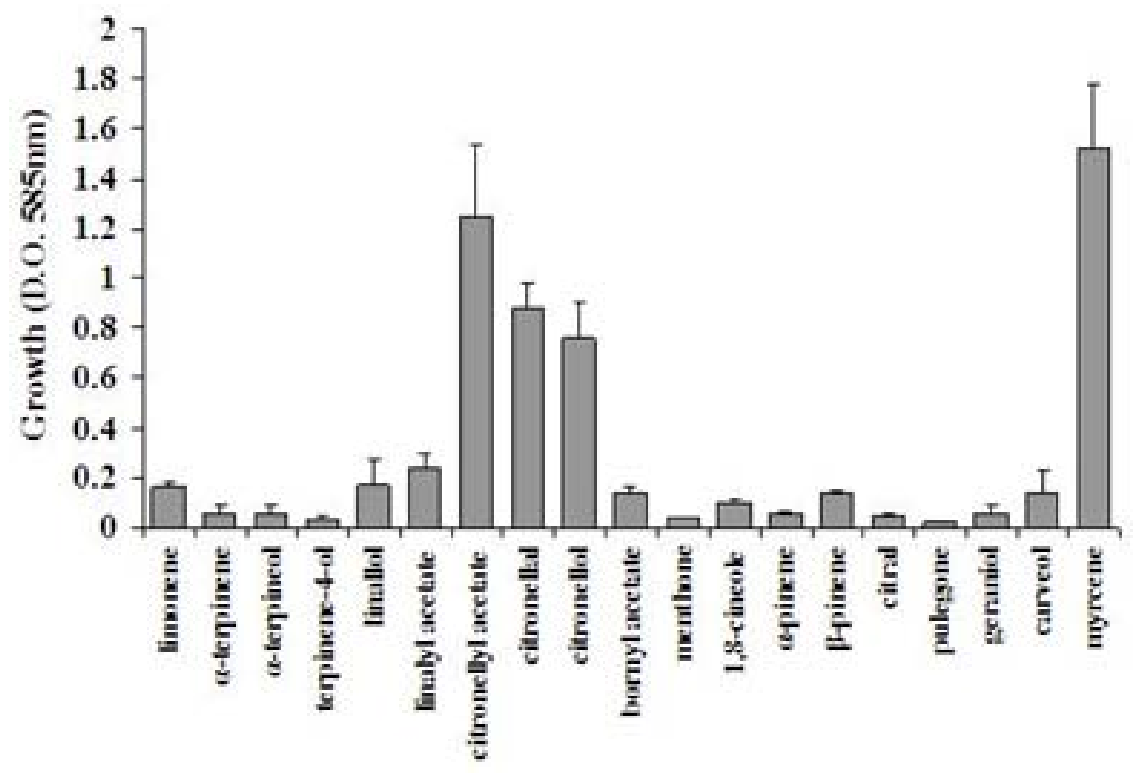

Figure 1. Spectrum of monoterpenes degradation by Pseudomonas mendocina IBPse 105.

principal hydrocarbon chain that makes the degradation of these compounds particularly recalcitrant (Föster-Fromme et al. 2006). However, several bacteria, particularly Pseudomonas ( $P$. aeruginosa, $P$. citronellolis, and $P$. mendocina), can use these compounds as sole carbon source (Cantwell et al. 1978; Campos-García and SoberónChávez, 2000; Díaz-Pérez et al. 2004). To degrade citronellol, Pseudomonas oxidized this alcohol to its aldehyde, and this to the corresponding acid, by what is known as the upper pathway. In the lower pathway, a carboxilation, a hydration and the removal of acetil-CoA leads to the production of 3-oxo-7-methyloctanoyl-CoA, which is transformed in 3-methylcrotonoyl-CoA by two rounds of oxidation. This metabolite is then metabolized by the leucine catabolic pathway producing acetil-CoA and acetoacetate (Díaz-Pérez et al. 2004; Höschle et al. 2005; Aguilar et al. 2006; Föster-Fromme et al. 2006).

Two gene clusters are involved in the catabolic pathways for acyclic monoterpenes in $P$. aeruginosa: the atu cluster (atuABCDEFG) responsible for the lower pathway, and the liu cluster (liuRABCDE) involved in both acyclic monoterpenes and leucine catabolism (Stover et al. 2000; Díaz-Pérez et al. 2004; Höschle et al. 2005; Aguilar et al. 2006; Föster-Fromme et al. 2006).

In the present paper, we report (i) the isolation and characterization of a citronellol degrading Pseudomonas medocina strain, (ii) the characterization of an insertion mutant deficient in citronellol degradation, and (iii) the study of the metabolism of citronellol, citronellal and citronellyl acetate by these bacterial strains.

\section{MATERIALS AND METHODS}

\section{Bacterial isolation}

Soil samples (3 g) from a citronella grass (Cymbopogon winterianus Jowitt) eight years old field at Caxias do Sul, RS, were suspended in $10 \mathrm{ml}$ distilled water. After decantation, a $2 \mathrm{ml}$ aliquot was transferred to $8 \mathrm{ml}$ of mineral salt medium (MM) (10), and incubated at $30^{\circ} \mathrm{C}$, $150 \mathrm{rpm}$ for $24 \mathrm{hrs}$. After this period citronellal $\left(1 \mathrm{~g} \mathrm{~L}^{-1}\right)$ was added and the flasks were incubated for $48 \mathrm{hrs}$ at $30^{\circ} \mathrm{C}$ and $150 \mathrm{rpm}$. Fifty $\mu \mathrm{l}$ aliquots of were plated on MM supplemented with $1.5 \%$ agar (Merck), and a $0.5 \mathrm{~cm}$ disk (Whatman $\left.\mathrm{N}^{\circ} 1\right)$ imbibed with citronellal $(10 \mu \mathrm{l})$ was deposited in the cover plate in order to generate a citronellal atmosphere. Plates were sealed with Parafilm and incubated upside down for five days at $30^{\circ} \mathrm{C}$. Bacterial colonies were purified and maintained on the above media.

\section{Phenotypic and genetic characterization of IBPse 105}

Phenotypic characterization of IBPse 105 included: Gram staining, oxidase, catalase, protease and lipase activity, biochemical tests for oxidase positive Gram negative bacteria (Bactray III, Laborclin), and bacterial growth on MM medium supplemented with different carbon sources (1 $\mathrm{g} \mathrm{L}^{-1}$ ) glucose, benzoate, diethanolamine, mannitol, sucrose, sorbitol, starch, inositol, citrate, and arabonose.

The universal primers 16S.F (5'CCAGCAGCCGCGGTAATACG-3') and 16SR (5'TACGGYTACCTTGTTACGACTTC-3') were used for PCR amplification and sequencing (Lu et al. 2000). DNA 


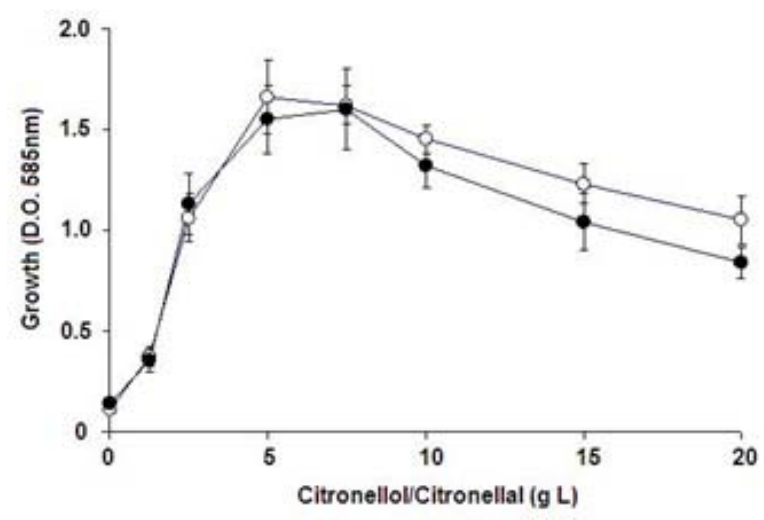

Figure 2. $P$. mendocina IBPse 105 growth in increasing concentrations of citronellal $(\mathrm{O})$ and citronellol $(\theta)$.

sequencing reactions were performed using the DYEnamic ET Dye terminator sequencing (MEGABASE) kit and run on a MegaBASE 1000 capillary sequencer (Amersham Biosciences).

\section{Bacterial growth on different monoterpenoids}

IBPse 105 was grown overnight at $30^{\circ} \mathrm{C}$ with shaking in MM supplemented with $5 \mathrm{~g} \mathrm{~L}^{-1}$ sodium citrate. Aliquots of this culture $(10 \mu \mathrm{l})$ were used to inoculate $1 \mathrm{ml}$ of $\mathrm{MM}$ medium supplemented with $0.1 \mathrm{~g} \mathrm{~L}^{-1}$ of the different terpenoids (Acros Organics, New Jersey) listed in Figure 1. The terpenoids used were practical grade with 90 to $95 \%$ purity. Tubes were incubated at $30^{\circ} \mathrm{C}$ with shaking for 72 hrs, and bacterial growth evaluated by absorbance readings at $580 \mathrm{~nm}$.

\section{Transposon mutagenesis and screening}

Transposon insertion mutants were generated by mobilizing the suicidal plasmid pUT miniTn5-Km2 (de Lorenzo et al.
1990) from E. coli S17-1( $\lambda$ pir) to P. mendocina IBPse 105. The IBPse 105 strain was grown overnight in Luria broth at $30^{\circ} \mathrm{C}$ with shaking, and the donor $E$. coli strain was grown at $37^{\circ} \mathrm{C}$ to the exponential phase. A 3:1 proportion of the donor and recipient cultures were placed on Luria agar plates, and incubated at $30^{\circ} \mathrm{C}$ for $10 \mathrm{hrs}$. The bacteria were suspended in sterile $\mathrm{NaCl}(0.9 \% \mathrm{w} / \mathrm{v})$ solution, and dilutions were spread on $\mathrm{MM}$ with $5 \mathrm{~g} \mathrm{~L}^{-1}$ sodium citrate supplemented with chloranphenicol (30 mg. $\mathrm{L}^{-1}$ ) and kanamycin (50 mg. $\mathrm{L}^{-1}$ ). Two thousand chloramphenicol and kanamycin-resistant mutants were tested for their ability to grow on MM plates supplemented with either citronellal, citronellol (added as vapor), or $5 \mathrm{~g} \mathrm{~L}^{-1}$ sodium citrate $^{-1}$.

Chromosomal DNA of the mutant IBPse 105-303 was digested with EcoRI, cloned to plasmid pBluescript II $\mathrm{KS}(+)$, transformed into E. coli DH5 $\alpha$, and plated onto Luria agar containing amplicillin (100 $\mathrm{mg} \mathrm{L}^{-1}$ ) and kanamycin (40 mg L $\mathrm{L}^{-1}$ ). Plasmid DNA was extracted using the plasmid Mini Kit (Qiagen), and sequenced using the mini-Tn5 Km2 O'-end primer (CCTCTAGAGTCGACCTGCAG). Sequencing was performed using the DYEnamic ET Dye terminator sequencing (MEGABASE) kit and run on a MegaBASE 1000 capillary sequencer (Amersham Biosciences). Chromosomal DNA sequence database was searched by using BLASTN algorithm.

\section{Reverse transcription polymerase chain reactions}

IBPse105 and IBPse105-303 were grown on MM medium supplemented with $5 \mathrm{~g} \mathrm{~L}^{-1}$ citronellal for $48 \mathrm{hrs}$. Cells were lysed and RNA was selectively extracted using Trizol (Invitrogen) per the manufacturer's instructions. The resuspended RNA samples were treated with DNAse I (Invitrogen) to digest contaminating coextracted DNA. Total RNA was quantified spectrophotometrically at 260 nm (Biochrom Libra S12).

Table 1. Percent degradation and accumulation of intermediates by IBPse 105 and IBPse 105-303 cells grown for 24 hrs on citronellol, citronellal and citronellyl acetate.

\begin{tabular}{|l|c|c|c|c|}
\hline & \multicolumn{2}{|c|}{ IBPse 105 } & \multicolumn{2}{c|}{ IBpse105-Mut 303 } \\
\hline Carbon source & $\begin{array}{c}\% \\
\text { degradation }\end{array}$ & $\begin{array}{c}\text { \% } \\
\text { intermediates }\end{array}$ & $\begin{array}{c}\% \\
\text { \% } \\
\text { degradation }\end{array}$ & $\begin{array}{c}\text { (10) } \\
\text { intermediates }\end{array}$ \\
\hline Citronellol & $62.3 \pm 4.1$ & $19.6 \pm 2.2$ & $0.0 \pm 0.0$ & $0.1 \pm 0.3$ \\
\hline Citronellal & $72.1 \pm 2.7$ & $7.8 \pm 1.8$ & $70.4 \pm 3.2$ & $9.2 \pm 3.6$ \\
\hline Citronellyl acetate & $78.7 \pm 3.4$ & $9.4 \pm 2.6$ & $78.0 \pm 1.1$ & $97.1 \pm 4.7^{*}$ \\
\hline
\end{tabular}

${ }^{a} \%$ reduction of the carbon source peak area; ${ }^{b} \%$ of the peak area of the intermediates over the total area.

* In the case of citronellyc acid, citronellol was considered as intermediate. 
RT-PCR amplification was performed with 200 ng of RNA using the SuperScript One-Step RT-PCR with Platinum Taq system following the manufacturer's instruction (Invitrogen). The primers atuB-F (GGCCTGTTCGCAGGCCAGAC)and atuB-R (CGCGCTGACCATGGCCTTCA), and atuC-F (ATCGTCGTCGGCGGCTCCTA) and atuC-R (GTCACGCGGGTCGATCAGGC) were designed to amplified $a t u \mathrm{~B}$ and $a t u \mathrm{C}$ of $P$. mendocina.The appropriate no reverse transcriptase control was prepared to confirm the absence of contaminating DNA. Amplification products were separated on $2 \%$ agarose gels, stained with ethidium bromide, and visualized by UV transillumination.

\section{Metabolite analyses}

The strains were grown in $100 \mathrm{ml}$ of MM medium with $5 \mathrm{~g}$ L sodium citrate under shaking for 18 hrs. Cells were harvested by centrifugation and washed twice with MM medium. The pellet was suspended in the original volume with MM medium and citronellol, citronellal or citronellyl acetate $\left(5 \mathrm{~g} \mathrm{~L}^{-1}\right)$, were added to a final concentration. The suspension was incubated at $30^{\circ} \mathrm{C}$ under shaking, and aliquots were withdrawn at intervals or at the end of the incubation period and centrifuged at $10000 \mathrm{x}$ g for $10 \mathrm{~min}$.
Extractions were proceeded according with Díaz-Pérez et al. (2004).

Samples were analyzed by gas chromatography-mass spectrometry (GC-MS) using a Hewlett-Packard gas chromatograph (Model 6890) connected to a HewlettPackard mass detector (Model 5973) and equipped with a $30 \mathrm{~m}$ x $0.25 \mathrm{~mm}$ i.d. HP-Innowax capillary column. The column temperature was programmed at $60^{\circ} \mathrm{C}$ for $8 \mathrm{~min}$, rising to $180^{\circ} \mathrm{C}$ at $3^{\circ} \mathrm{C} / \mathrm{min}$, then to $230^{\circ} \mathrm{C}$ at $20^{\circ} \mathrm{C} / \mathrm{min}$, then held isothermal for $20 \mathrm{~min}$; injector temperature, $250^{\circ} \mathrm{C}$; detector temperature, $280^{\circ} \mathrm{C}$. The carrier gas was helium at a flow rate of $1.0 \mathrm{ml} / \mathrm{min}$. Mass spectra were recorded at $30-450 \mathrm{~m} / \mathrm{z}$. Individual components were identified by matching their $70 \mathrm{eV}$ mass spectra with those of the spectrometer database, using the Wiley Mass Spectral libraries, their retention times (RT) and their linear retention indices.

GC analysis was performed on a HP 5973 gas chromatograph with FID detector, using a HP-Innowax fused silica capillary column (30 m x $0.25 \mathrm{~mm}$ i.d., $0.50 \mu \mathrm{m}$ film thickness). The chromatographic conditions were: column temperature, $40^{\circ} \mathrm{C}$ for $8 \mathrm{~min}$, then rising to $180^{\circ} \mathrm{C}$ at $3^{\circ} \mathrm{C} / \mathrm{min}$, then to $230^{\circ} \mathrm{C}$ at $20^{\circ} \mathrm{C} / \mathrm{min}$, then held at $230^{\circ} \mathrm{C}$ for

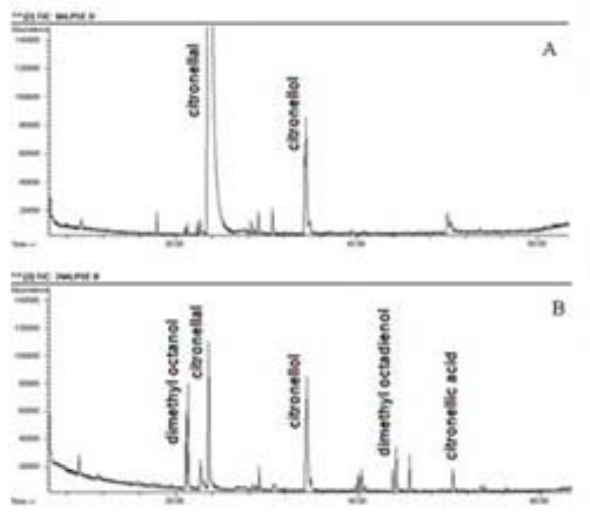

I
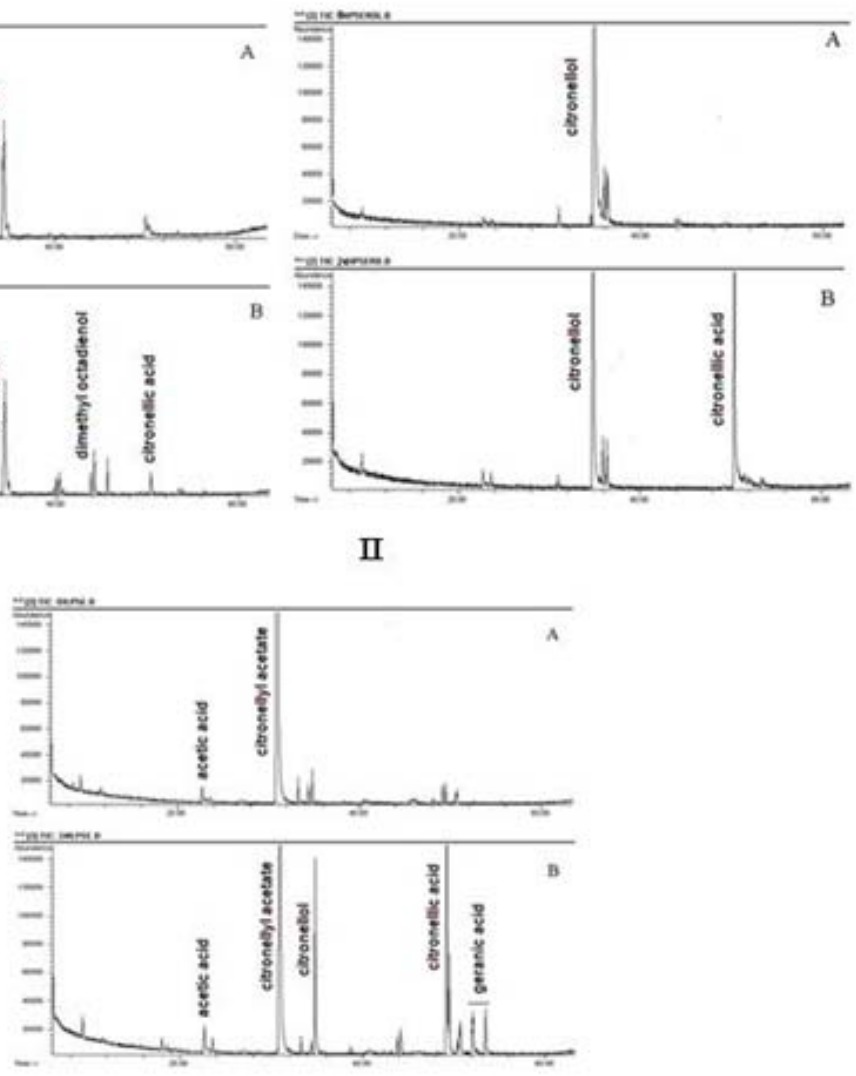

III

Figure 3. Monoterpenes degradation and metabolite accumulation in cultures of $P$. mendocina IBPse 105 grown in citronellal (I), citronellol (II) and citronellyl acetate (III). Supernatant extractions and analyses were done at time 0 (A) and $12 \mathrm{hrs}$ (B). 
$20 \mathrm{~min}$; injector temperature, $250^{\circ} \mathrm{C}$; split ratio, 1:50; detector temperature, $250^{\circ} \mathrm{C}$; carrier gas, hydrogen at 34 $\mathrm{KPa}$; flow rate, $1.0 \mathrm{ml} / \mathrm{min}$; volume injected, $0.2 \mu \mathrm{l}$. Chemical analyses were performed in triplicate.

\section{RESULTS AND DISCUSSION}

Based on colony morphology, two different citronellal degrading bacteria were isolated from soil samples obtained from a citronella grass (Cymbopogon winterianus Jowitt) field, a plant which essential oil is characterized by high concentration of citronellal (35.9\%) and geraniol (20.9\%) (Cassel and Vargas, 2006).

One of these bacteria exhibited fast growth on citronellal, and was selected for subsequent studies. Their colonies on MM citrate agar were circular, brilliant and yellow, and the cells were Gram-negative straight rods. Catalase and oxidase reactions were positive, and lipolytic and proteolytic activities were negatives. This bacterium grew well on cetrimide medium, but did not produce visible pigments or fluorescence. It use glucose, citrate, maltose, manitol, and benzoate as carbon sources, but gave negative results for sucrose, sorbitol, starch, inositol, arabinose, lactose, esculin, acetamide, diethanolamide, urease, and indol tests. Growth occurred between $15^{\circ} \mathrm{C}$ and $40^{\circ} \mathrm{C}$.

The morphological characteristics, biochemical test, and the ability to grow on citronellal as carbon source, allowed classifying this bacterium (IBPse 105) as Pseudomonas mendocina or $P$. citronellolis. Moreover, 16S rRNA sequence from strain IBPse 105 (980 bp) showed high similarity (99-100\%) with that of different strains of $P$. mendocina, and less than $96 \%$ similarity with $P$. citronellolis.

Also cited in several works, the only description of a $P$. mendocina strain growing on acyclic monoterpenes (citronellol, geraniol, and nerol) was made by Cantwell et al. (1978).

The ability of IBPse 105 to grow in the presence of 19 monoterpenes $\left(1 \mathrm{~g} \mathrm{~L}^{-1}\right)$ as the only source of carbon was evaluated. As shown in Figure 1, this strains is able to grow in citronellol, citronellal, citronellyl acetate, and myrcene, but exhibited just residual growth on other acyclic (geraniol, citral, linallol, and linallyl acetate) and cyclic (limonene, bornyl acetate, terpinen-4-ol, $\alpha$-terpineol, terpinene, 1,8-cineol, menthene, pulegone, carveol, $\alpha$ pinene, and $\beta$-pinene).

The spectrum of degradation of monoterpenes of $P$. mendocina IBPse 105 is restricted when compared with that of P. mendocina ATCC 25411 (Cantwell et al. 1978), and other species of the genus (Cantwell et al. 1978; Díaz-Pérez et al. 2004; Föster-Fromme et al. 2006).

Although both are acyclic monoterpenes, the degradation of citronellol and myrcene is achieved by different catabolic pathways with specific genes and enzymes (Iurescia et al.
1999; Höschle et al. 2005; Aguilar et al. 2006; FösterFromme et al. 2006). Conversely, the citronellol and geraniol degradation pathways share most of the enzymes, and the ability of IBPse 105 to use just one of these monoterpenes, confirms the existence of different metabolic routes (upper pathway) for their oxidation (Höschle and Jendrossek, 2005).

Experiment on increasing concentrations of citronellol and citronellal showed that induced (cells grown on $1 \mathrm{~g} \mathrm{~L}^{-1}$ citronellol) $P$. mendocina IBPse 105 reached its maximum growth on 5 to $7.5 \mathrm{~g} \mathrm{~L}^{-1}$, exhibiting a progressive decrease in higher concentrations (Figure 2). The reduction on bacterial growth can be attributed to toxic effects exerted by high concentrations of these monoterpenes, which are known to possess antimicrobial activity (Dorman and Deans, 2000; Bakkali et al. 2008). As reported by Cantwell et al. (1978) for $P$. citronellolis and $P$. aeruginosa, drastic reduction ( $>90 \%$ ) on $P$. mendocina IBPse 105 cell viability occurred when non-induced cell were added to citronellol and citronellal $\left(1.0 \mathrm{mg} \mathrm{L}^{-1}\right)$ containing media (data not shown).

Chromatographic analyses of culture medium during IBPse 105 growth on citronellal, citronellol and citronellyl acetate allowed identifying several metabolites. As can be observed in Figure 3, metabolites accumulated during citronellal, citronellol and citronellyl acetate degradation, particularly citronellic and geranic acids, are in accordance with those previously reported on $P$. aeruginosa and $P$. citronellolis (Díaz-Pérez et al. 2004; Höschle et al. 2005; Aguilar et al. 2006; Föster-Fromme et al. 2006), indicating that $P$. mendocina uses the general citronellol catabolic pathway described for these bacteria. Citronellol in citronellal control sample (Figure 3IA), as well as dimethyl octanol

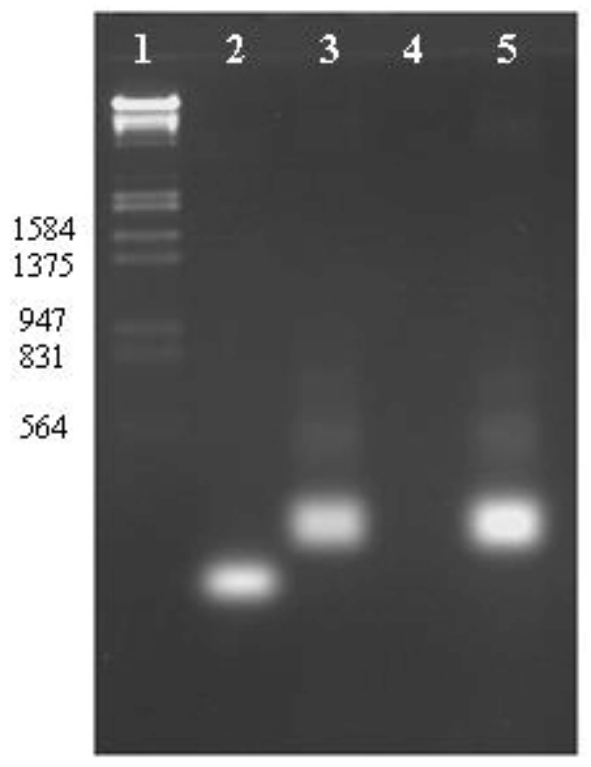

Figure 4. atuB and atuC gene expression (RT-PCR) in the wild strain IBPse 105 and its insertion mutant IBPse 105303 grown in citronellal MM medium. 

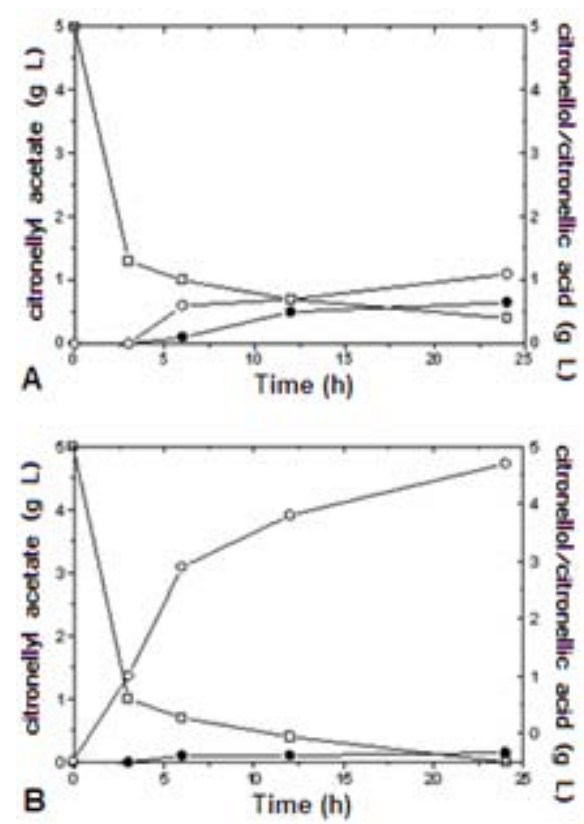

Figure 5. Citronellyl acetate degradation by $P$. mendocina IBPse 105 (A) and its mutant IBPse 105-303 (B). Citronellyl acetate $(\square)$, citronellol $(\mathrm{O})$ and citronellic acid $(\mathbf{D})$.

and dimethyl octadienol (Figure 3IB), were contaminants of the practical grade citronellal (93\% purity) used in media preparation.

A BLAST analysis of the P. medocina genome (Copeland et al. 2007) confirms the presence of homologous of the atuABCDEF genes of $P$. aeruginosa and $P$. citronellolis in this species, corroborating the above data.

The accumulation of citronellol during citronellyl acetate metabolism indicates that $P$. mendocina IBPse 105 hydrolyze the acetate to free alcohol, which is further metabolized by the citronellol catabolic pathway. These data corroborate those obtained by Madyastha and Renganathan (1983) for $P$. incognita acyclic monoterpene acetates degradation, and differs from the results obtained for the utilization of the cyclic monoterpenoid linalyl acetate (Renganathan and Madyastha, 1983).

To further stud the catabolic pathway involved in acyclic monoterpenes degradation by $P$. mendocina, a library of kanamycin resistant mutants was generated mini-Tn5 transposon from plasmid pUT:Km2. Two thousand mutants were screened for their ability to grow on citronellol as only source of carbon. Seven mutants were selected, all showing the same growth phenotype. They grow on sodium citrate, citronellal, citronellyl acetate, and mircene, but not on citronellol, suggesting that the mutations were caused by a single transposition event. The sequence of a $254 \mathrm{pb}$ transposon franking region of mutant IBPse 105-303 showed that insertion had occurred approximately $150 \mathrm{bp}$ from the origin of the $a t u B$ gene. AtuB codify the first enzyme of the citronellol catabolic pathway, citronellol dehydrogenase, that oxidize citronellol to citronellal (Föster-Fromme et al. 2006).

To confirm the expression of atu genes, two sets of primers were constructed based on the $a t u B$ and $a t u C$ genes of $P$. mendocina. Atu $B$ primers were designed to amplified a region of 229 bp that include the transposon insertion region (aprox. $120 \mathrm{bp}$ from gene origin) previously defined by sequencing. PCR products of both genes were obtained on IBPse 105, but as expected, just atuC amplicon was detected on IBPse 105-303. To confirm the expression of atu genes on the insertional mutant, RT-PCR analysis of IBPse 105 and IBPse 105-303 grown on citronellol containing medium showed the expression of $a t u C$ in both strains, and $a t u B$ only in the wild type IBPse 105 strain (Figure 4). These data differed from those obtained by Föster-Fromme et al. (2006) which observed polar downstream effect of $a t u B$ mini-Tn5-Tc insertions. However, the same authors reported non polar downstream effect on pKnockout-derived mutants in which the lac promoter was orientated collinearly to the gene cluster (Fröster-Fromme et al. 2006). Different from mini-Tn5-Tc, pKnockout and pUT:Km2 do not carry terminators, allowing the expression of downstream genes (de Lorenzo et al. 1990).

A comparison between IBPse 105 wild type and IBPse-303 mutant on media supplemented with citronellol, citronellal or citronellyl acetate (Table 1) showed that both degrade citronellal and citronellyl acetate, but the mutant was not able to degrade citronellol. Moreover, growing in citronellyl acetate, IBPse 105-303 accumulated citronellol over time as an intermediate metabolite, differing from the wild type strain (Figure 5).

In summary, the present data showed that $P$. mendocina IBPse 105 efficiently degrade citronellol, citronellal and citronellyl acetate using the citronellol catabolic pathway previously described in $P$. aeroginosa and $P$. citronellolis. Moreover, results obtained with wild type IBPse 105 and its insertional mutant (IBPse 105-303) confirms the initial hydrolysis of citronellyl acetate to its alcohol.

\section{REFERENCES}

AGUILAR, J.A.; ZAVALA, A.N.; DÍAZ-PÉREZ, C.; CERVANTES, C.; DÍAZ-PÉREZ, A.L. and CAMPOSGARCÍA, J. The atu and liu clusters are involved in the catabolic pathways for acyclic monoterpenes and leucine in Pseudomonas aeruginosa. Applied and Environmental Microbiology, March 2006, vol. 72, no. 3, p. 2070-2079.

BAKKALI, F.; AVERBECK, S.; AVERBECK, D. and IDOAMAR, M. Biological effects of essential oils - a review. Food and Chemical Toxicology, February 2008, vol. 46, no. 2, p. 446-475. 
CAMPOS-GARCÍA, Jesús and SOBERÓN-CHÁVEZ, Gloria. Degradation of the methyl substituted alkene, citronellol, by Pseudomonas aeruginosa, wild type and mutant strains. Biotechnology Letters, February 2000, vol. 22, no. 3, p. 235-237.

CANTWELL, Susan G.; LAU, Edward P.; WATT, David S. and FALL, R. Ray. Biodegradation of acyclic isoprenoids by Pseudomonas species. Journal of Bacteriology, August 1978, vol. 135, no. 2, p. 324-333.

CASSEL, Eduardo and VARGAS, Rubem M.F. Experiments and modeling of the Cymbopogon winterianus essential oil extraction by stream distillation. Journal of the Mexican Chemical Society, 2006, vol. 50, no. 3, p. 126-129.

COPELAND, A.; LUCAS, S.; LAPIDUS, A.; BARRY, K.; GLAVINA DEL RIO, T.; DALIN, E.; TICE, H.; PITLUCK, S.; KISS, H.; BRETTIN, T.; DETTER, J. C.; BRUCE, D.; HAN, C.; SCHMUTZ, J.; LARIMER, F.; LAND, M.; HAUSER, L.; KYRPIDES, N.; MIKHAILOVA, N.; HERSMAN, L.; DUBOIS, J.; MAURICE, P. and RICHARDSON, P. Complete sequence of Pseudomonas mendocina ymp [online]. National Center of Biotechnology Information, April 2007. Available from Internet:

http://www.ncbi.nlm.nih.gov/nuccore/NC_009439.

DE LORENZO, Victor; HERRERO, Marta; JAKUBZIK, Ute and TIMMIS, Kenneth N. Mini-Tn5 transposon derivatives for insertion mutagenesis, promoter probing, and chromosomal insertion of cloned DNA in gramnegative eubacteria. Journal of Bacteriology, November 1990, vol. 172, no. 11, p. 6568-6572.

DÍAZ-PÉREZ, A.L.; ZAVALA-HERNANDES, A.N.; CERVANTES, C. and CAMPOS-GARCÍA, J. The gnyRDBHAL cluster is involved in acyclic isoprenoid degradation in Pseudomonas aeruginosa. Applied and Environmental Microbiology, September 2004, vol. 70, no. 9, p. 5102-5110.

DORMAN, H.J.D. and DEANS, S.G. Antimicrobial agents from plants: antibacterial activity of plant volatile oils. Journal of Applied Microbiology, February 2000, vol. 88, no. 2, p. 308-316.

FÖSTER-FROMME, Karin; HÖSCHLE, Birgit; MACK, Christina; BOTT, Michael; ARMBRUSTER, Wolfgang and JENDROSSEK, Dieter. Identification of genes and proteins necessary for catabolism of acyclic terpenes and leucine/isovalerate in Pseudomonas aeruginosa. Applied and Environmental Microbiology, July 2006, vol. 72, no. 7, p. 4819-4828.

HAMMER, K.A.; CARSON, C.F. and RILEY, T.V. Antimicrobial activity of essential oils and other plant extracts. Journal of Applied Microbiology, January 1999, vol. 86, no. 6, p. 987-990.
HÖSCHLE, Birgit and JENDROSSEK, Dieter. Utilization of geraniol is dependent on molybdenum in Pseudomonas aeruginosa: evidence for different metabolic routes for oxidation of geraniol and citronellol. Microbiology, July 2005, vol. 151, no. 7, p. 2277-2283.

HÖSCHLE, Birgit; GNAU, Volker and JENDROSSEK, Dieter. Methylcrotonyl-CoA and geranyl-CoA carboxylases are involved in leucine/isovalerate utilization (Liu) and in acyclic terpenes utilization (Atu) and are encoded by liuB/liuD and atuC/atuF, in Pseudomonas aeruginosa. Microbiology, November 2005, vol. 151, no. 11, p. 36493646.

IURESCIA, Sandra; MARCONI, Andrea M.; TOFANI, Daniela; GAMBACORTA, Augusto; PATERNÒ, Annalisa; DEVIRGILIS, Chiara; VAN DER WERF, Mariët and ZENNARO, Elizabetta. Identification and sequencing of $\beta$-myrcene catabolism genes from Pseudomonas sp. Strain M1. Applied Environmental Microbiology, July 1999, vol. 65, no. 7, p. 2871-2876.

LU, Jang-Jih; PERNG, Cherng-Lih; LEE, Shih-Yi and WAN, Chih-Chieng. Use of PCR with universal primers and restriction endonuclease digestions for the detection and identification of common bacterial pathogens in cerebrospinal fluid. Journal Clinical Microbiology, June 2000, vol. 38, no. 6, p. 2076-2080.

LOZA-TAVERA, Herminia. Monoterpenes in essential oils. In: SHAHIDI, F.; KOLODZIEJCZYK, P.; WHITAKER, J.R.; MUNGUIA, A.L. and FULLER, G. eds. Chemical via higher plant bioengineering, Springer; Berlin, 1999, p. 49-61.

MADYASTHA, M.K. and RENGANATHAN, V. Biodegradation of acetates of geraniol, nerol and citronellol by $P$. incognita: isolation and identification of metabolies. Indian Journal of Biochemistry and Biophysics, 1983, vol. 20, no. 3, p. 136-140.

RENGANATHAN, V. and MADYASTHA, M.K. Linalyl acetate is metabolize by $P$. incognita with the acetoxy group intact. Applied Environmental Microbiology, January 1983, vol. 45, no. 1, p. 6-15.

STOVER, C.K.; PHAM, X.Q.; ERWIN, A.L.; MIZOGUCHI, S.D.; WARRENER, P.; HICKEY, M.J.; BRINKMAN, F.S.; HUFNAGLE, W.O.; KOWALIK, D.J.; LAGROU, M.; GARBER, R.L.; GOLTRY, L.; TOLENTINO, E.; WESTBROCK-WADMAN, S.; YUAN, Y.; BRODY, L.L.; COULTER, S.N.; FOLGER, K.R.; KAS, A.; LARBIG, K.; LIM, R.; SMITH, K.; SPENCER, D.; WONG, G.K.; WU, Z.; PAULSEN, I.T.; REIZER, J.; SAIER, M.H.; HANCOCK, R.E.; LORY, S. and OLSON, M.V. Complete genome sequence of Pseudomonas aeruginosa PA01, an opportunistic pathogen. Nature, 2000, vol. 406, no. 6799, p. 959-964. 